\title{
Flexible Nasal Endoscopic Procedures in Family Medicine: Indications and Effectiveness
}

\author{
John Malaty, MD; Dongyuan Wu, MS; Susmita Datta, PhD
}

\begin{abstract}
BACKGROUND AND OBJECTIVES: Most literature about flexible nasolaryngoscopy comes from specialty clinics, making it unclear if these indications can be effectively managed without referral. This study evaluated effectiveness of diagnosis and management of upper airway complaints, utilizing flexible nasal endoscopic procedures, in a family medicine center.
\end{abstract}

METHODS: We performed retrospective chart review for all patients who had nasal endoscopy, nasopharyngoscopy, and nasolaryngoscopy performed at the University of Florida Family Medicine Center over 3 years $(n=89)$ with 5 additional years of follow up. We used descriptive statistics to evaluate indications, diagnoses, effectiveness of management by family medicine, and referral rate.

RESULTS: The most common primary indications were hoarseness $(n=33$, $37 \%)$, chronic cough $(n=20,22 \%)$, nasal obstruction $(n=9,10 \%)$, and unilateral ear dysfunction $(n=6,7 \%)$. The most common primary diagnoses found were allergic rhinitis/postnasal drip $(n=41,46 \%)$, laryngopharyngeal reflux (LPR)/gastroesophageal reflux disease (GERD; $n=24,27 \%$ ), masses concerning for malignancy $(n=4,4.5 \%)$, true vocal cord (TVC) polyp $(n=3,3 \%)$, TVC nodules $(n=3,3 \%)$, and epistaxis $(n=3,3 \%)$. Of the four concerning masses, two were confirmed cancers (2\%). In addition, there was one case $(1 \%)$ of erythroleukoplakia with dysplasia of the TVC. Most patients had documented improvement with family medicine management $(n=57,64 \%)$ and another six $(7 \%)$ had follow up without documentation of status and no need for referral. Thus, a total of $71 \%(n=64)$ did not require referral and $20 \%(n=18)$ needed specialist referral.

CONCLUSIONS: Flexible nasal endoscopic procedures are effective in the care of patients in a family medicine residency center and can be safely performed and taught to residents.

(Fam Med. 2021;53(10):886-9.)

doi: 10.22454/FamMed.2021.332061

$\mathrm{n}$ the primary care setting, many ear, nose, and throat concerns are within the purview of primary care physicians and can be further evaluated with flexible nasolaryngoscopy. ${ }^{1}$ Questions arise as to whether it is still worthwhile to teach residents how to do these procedures.
Flexible nasolaryngoscopy is performed in clinic and provides visualization of the nasal cavity, nasopharynx, oropharynx, hypopharynx, and larynx. Common indications in primary care have been noted to include hoarseness, chronic cough, globus sensation, reflux, and sore throat. ${ }^{2}$ Unfortunately, there is limited data about how frequently this procedure is currently performed by primary care, with it being previously noted that $6 \%$ of family physicians performed this procedure in 2008. In addition, most literature about flexible nasolaryngoscopy comes from specialty clinics, making it unclear which indications are most common in the primary care setting and if these can be managed by family medicine, without need for referral. ${ }^{3-7}$ Furthermore, findings during flexible nasolaryngoscopy can help diagnose the etiology for patients' symptoms to facilitate management and either identify early malignancy or provide reassurance that no cancer is present. ${ }^{7,8}$ This is beneficial in the primary care setting since there are fewer specialists in rural settings and higher rates of cancer and increased mortality in those settings, caused by modifiable risk factors. ${ }^{9-11}$ In addition, there are increased health care costs associated with referrals to specialists and evidence of variable referral rates and increasing referral rates in family medicine clinics. ${ }^{12,13}$ This study aimed to evaluate the use of flexible nasal endoscopic procedure (FNEP) in a family medicine residency clinic to determine the indications for FNEP, the

From the Department of Community Health and Family Medicine (Dr Malaty), and Department of Biostatistics (Dr Datta and Ms Wu), University of Florida, Gainesville, FL. 
common diagnoses of upper airway complaints using FNEP, the efficacy of management of conditions diagnosed by FNEP, and rates of referral to a specialist.

\section{Methods}

This is an institutional review boardapproved retrospective chart review of all patients who had flexible nasal endoscopic procedures FNEP performed at the University of Florida Family Medicine Center (FMC) from July 1, 2011 through September 1, 2014 , with 5 additional years of patient follow up. This FMC is the site for family medicine resident clinics and residency faculty clinics. The charts were located via billing data for Current Procedural Terminology codes 31291 (nasal endoscopy), 92511 (nasopharyngoscopy), and 31575 (nasolaryngoscopy). We reviewed all charts and extracted relevant data manually. Data evaluated included procedure type, indication for procedures, diagnoses, whether patients were successfully managed in family medicine clinic without referral (resolution of symptoms/findings with treatment), and referral rate. All procedures were either performed by or supervised by the lead author (when residents performed procedures). FNEP were performed using an Olympus ENF-P4 fiber rhinolaryngoscope. We performed descriptive statistical analyses on all aforementioned data.

\section{Results}

A total of 89 FNEP were performed during the study period. Seventy were flexible nasolaryngoscopy, 10 were flexible nasal endoscopy, and nine were flexible nasopharyngoscopy. Fifty-two (58.4\%) were performed on women and $37(41.6 \%)$ were performed on men. The average age of patients was 54 years. Age range was 16-87 years old with standard deviation of 14.4 years. All patients tolerated the procedures well and there were no complications.
The most common primary indications were hoarseness $(\mathrm{n}=33,37 \%)$, chronic cough $(\mathrm{n}=20,22 \%)$, nasal obstruction $(n=9,10 \%)$, and unilateral ear dysfunction ( $\mathrm{n}=6,7 \%$; Table 1$)$.

The three most common indications were caused mostly by allergic rhinitis/postnasal drip or laryngopharyngeal reflux (LPR)/gastroesophageal reflux disease (GERD), compared to all other etiologies combined (Table 1) and only three of the combined 65 cases $(4.61 \%)$ required referral for refractory symptoms (Table 2).

Primary diagnoses found most frequently were allergic rhinitis/ postnasal drip ( $n=41,46 \%), \mathrm{LPR}$ or GERD ( $\mathrm{n}=24,27 \%)$, masses concerning for malignancy $(\mathrm{n}=4,4.5 \%)$, true vocal cord (TVC) polyp ( $\mathrm{n}=3,3 \%)$, TVC nodules $(n=3,3 \%)$, and further evaluation of epistaxis $(n=3$, $3 \%$; Table 2). Of the four masses that were concerning for malignancy, two were confirmed cancers (2\%). In addition, there was one case (1\%)

Table 1: Primary Indications for Flexible Nasal Endoscopic Procedures in a Family Medicine Center

\begin{tabular}{|l|c|c|c|c|}
\hline \multicolumn{1}{|c|}{ Primary Indication } & $\begin{array}{c}\text { Total, N=89 } \\
\mathbf{n}(\%)\end{array}$ & $\begin{array}{c}\text { Postprocedural } \\
\text { Diagnosis of Allergic } \\
\text { Rhinitis,+ N=41 } \\
\mathbf{n}(\%)\end{array}$ & $\begin{array}{c}\text { Postprocedural } \\
\text { Diagnosis of LPR/ } \\
\text { GERD,+ N=24 } \\
\mathbf{n}(\%)\end{array}$ & $\begin{array}{c}\text { Postprocedural } \\
\text { Diagnoses: } \\
\text { Other Etiologies } \\
\text { (Combined),+ N=24 } \\
\mathbf{n} \text { (\%) }\end{array}$ \\
\hline Hoarseness & $33(37.1)$ & $16(48.5)$ & $7(21.2)$ & $10(30.3)$ \\
\hline Chronic cough & $20(22.5)$ & $10(50.0)$ & $8(40.0)$ & $2(10.0)$ \\
\hline Nasal obstruction & $9(10.1)$ & $6(66.7)$ & $0(0.0)$ & $3(33.3)$ \\
\hline Unilateral ear dysfunction* & $6(6.8)$ & $2(33.3)$ & $0(0.0)$ & $4(66.7)$ \\
\hline Globus sensation & $4(4.5)$ & $2(50.0)$ & $2(50.0)$ & $0(0.0)$ \\
\hline Throat pain & $4(4.5)$ & $1(25.0)$ & $3(75.0)$ & $0(0.0)$ \\
\hline Hemoptysis & $3(3.4)$ & $0(0.0)$ & $2(66.7)$ & $1(33.3)$ \\
\hline Dysphagia & $3(3.4)$ & $1(33.3)$ & $1(33.3)$ & $1(33.3)$ \\
\hline Epistaxis & $2(2.3)$ & $0(0.0)$ & $0(0.0)$ & $2(100.0)$ \\
\hline Throat clearing & $2(2.3)$ & $2(100.0)$ & $0(0.0)$ & $0(0.0)$ \\
\hline Anterior neck pain, chronic & $1(1.1)$ & $0(0.0)$ & $1(100.0)$ & $0(0.0)$ \\
\hline Coughing when eating & $1(1.1)$ & $0(0.0)$ & $0(0.0)$ & $1(100.0)$ \\
\hline Nasal pain & $1(1.1)$ & $1(100.0)$ & $0(0.0)$ & $0(0.0)$ \\
\hline
\end{tabular}

Abbreviations: LPR, laryngopharyngeal reflux; GERD, gastroesophageal reflux.

*Unilateral acute otitis media $(\mathrm{n}=1,1.1 \%)$, eustachian tube dysfunction $(\mathrm{n}=2,2.3 \%)$, middle-ear effusion $(\mathrm{n}=1,1.1 \%)$, and otalgia $(\mathrm{n}=2,2.3 \%)$ were combined into a category of "unilateral ear dysfunction" ( $\mathrm{n}=6,6.75 \%)$ for analysis. Both cases of eustachian tube dysfunction were indicative of underlying allergic rhinitis.

+ The percentage of patients with a primary indication that were diagnosed with allergic rhinitis, LPR/GERD, and all other etiologies (combined). 
Table 2: Primary Diagnoses After Flexible Nasal Endoscopic Procedures Were Performed in a Family Medicine Center

\begin{tabular}{|l|c|c|}
\hline \multicolumn{1}{|c|}{ Primary Diagnoses } & $\begin{array}{c}\text { Total, N=89 } \\
\mathbf{n}(\%)\end{array}$ & $\begin{array}{c}\text { Need for Referral, N=18 } \\
\mathbf{n}(\%)\end{array}$ \\
\hline Allergic rhinitis/postnasal drip & $41(46.1)$ & $2(4.9)$ \\
\hline LPR/GERD & $\begin{array}{c}\text { GERD/LPR } \\
24(27.0) \\
\text { GERD: 7 (7.9) } \\
\text { LPR: } 17(19.1)\end{array}$ & $\begin{array}{c}\text { GERD: } 0(0.0) \\
\text { LPR: } 1(5.9)\end{array}$ \\
\hline Masses concerning for malignancy* & $4(4.5)$ & $4(100.0)$ \\
\hline True vocal cord polyp & $3(3.4)$ & $3(100.0)$ \\
\hline True vocal cord nodules & $3(3.4)$ & $2(66.7)$ \\
\hline Epistaxis & $3(3.4)$ & $0(0)$ \\
\hline True vocal cord paralysis & $2(2.3)$ & $2(100.0)$ \\
\hline Nasal polyps & $2(2.3)$ & $2(100.0)$ \\
\hline Acute otitis media and otitis media with effusion, unilateral & $2(2.3)$ & $0(0.0)$ \\
\hline Erythroleukoplakia, true vocal cords & $1(1.1)$ & $1(100.0)$ \\
\hline Esophageal spasm & $1(1.1)$ & $0(0.0)$ \\
\hline Septal deviation & $1(1.1)$ & $0(0.0)$ \\
\hline TMJ syndrome, unilateral & $1(1.1)$ & $0(0.0)$ \\
\hline No etiology determined & $1(1.1)$ & $1(100.0)$ \\
\hline
\end{tabular}

Abbreviations: LPR, laryngopharyngeal reflux; GERD, gastroesophageal reflux; TMJ, temporomandibular joint dysfunction.

*Supraglottic mass $(\mathrm{n}=1,1.1 \%)$, true vocal cord mass $(\mathrm{n}=1,1.1 \%)$, and nasopharyngeal mass $(\mathrm{n}=2,2.3 \%)$ were combined into a category of "masses concerning for malignancy" $(\mathrm{n}=4,4.5 \%)$ for analysis.

+ The percentage of patients with a primary diagnosis that required referral for that diagnosis

of erythroleukoplakia with dysplastic changes of the TVC that required close monitoring to ensure there was not malignant transformation (Table 2).

Notable secondary diagnoses included gastroparesis ( $\mathrm{n}=3,5.88 \%)$, nasal polyps when unrelated to primary concern $(n=3,5.88 \%)$, visualized aspiration of secretions $(\mathrm{n}=2,3.92 \%)$, chronic sinusitis $(\mathrm{n}=2$, $3.92 \%)$, rhinitis medicamentosa $(\mathrm{n}=1$, $1.96 \%$ ), and endoscopic findings of obstructive sleep apnea $(n=1,1.96 \%)$. Percentages for secondary diagnoses reflect percentage of all secondary diagnoses.

Of the 89 patients that had FNEP, $57(64 \%)$ had documented improvement and did not require referral and another six (7\%) had follow up in clinic without documentation of status and no need for referral. Eighteen $(20 \%)$ patients were referred to a specialist. Seventeen patients were referred to otolaryngology and one was referred to gastroenterology. Reasons for referral are listed in Table 2. Of those referred, 15 (17\%) were referred without treatment for concerns requiring specialty evaluation/management and three $(3 \%)$ were referred for uncontrolled problems despite management by family medicine.

\section{Discussion}

This is the first report that evaluates the effectiveness of managing conditions diagnosed with FNEP in a teaching FMC and only the second sizeable, recent report that looks at indications, diagnoses, and referral rates within a family medicine clinic. ${ }^{2}$ Most patients had documented improvement and did not require referral $(64 \%)$, while an additional $7 \%$ of patients did not have documentation of the status of the previously treated problem and did not require referral. It is likely that the status was not documented at follow up because patients were doing well, and thus, other concerns were addressed. Thus, in total, $71 \%$ of patients did not require referral; referral rate was only $20 \%$.

Most common diagnoses were allergic rhinitis/postnasal drip and LPR/GERD, and these were managed well in our FMC, with only 3/65 cases $(4.61 \%)$ requiring referral for refractory symptoms. In select cases, this included management of comorbidities (secondary diagnoses), such as gastroparesis, that are not typically managed by otolaryngology.

Additional diagnoses for whom specialty care was needed included masses concerning for malignancy, erythroleukoplakia of the TVC, TVC polyp, TVC nodules, TVC paralysis, nasal polyps, and a single case where etiology was unclear. Referrals were made to the appropriate subspecialty, which minimized additional referrals. For instance, instead of referring to general ear, nose, throat 
(ENT), referrals were typically made to ENT oncology, laryngology, or rhinology to streamline care.

Our low prevalence of laryngeal cancer is consistent with $3 \%$ prevalence found when primary care screened smokers more than 40 years old for head and neck cancer and referred to otolaryngology to have flexible nasolaryngoscopy. ${ }^{14}$ This low prevalence further supports evaluation by primary care since most patients have other conditions that can be managed by family medicine, with only a small percentage requiring referral.

All procedures were either supervised by or performed by the lead author. The advantage of this is that it allows for consistency of reported findings, especially in a family medicine center where residents performed some of the procedures. One potential limitation of this study is that it raises the question about whether these findings are reproducible by others. However, similar findings were reported in the past in a family medicine clinic, which supports that this data can be reproducible. ${ }^{2}$ Other potential limitations are limited number of faculty trained to teach FNEP, which requires further study, and potential cost of equipment. In our family medicine center, the rhinolaryngoscope cost $\$ 3,000$ and it was paid off after performing 30 procedures (within a year) and we have been using the same equipment for 10 years. It is financially feasible. However, newer digital rhinolaryngoscopes are available so financial feasibility would need to be further investigated with this new equipment. It is also possible that not enough procedures will need to be performed to maintain procedural competency in practice, but based on the number of procedures needed in our center and the minimal number needed per year to maintain competency, we did not find this to be the case, even in the past when three physicians were sharing these procedures. However, future studies are needed to ensure this is generalizable.

FNEP are well tolerated and quick, 5 -minute procedures with very low risk. ${ }^{15}$ Patient benefits include enhanced diagnosis and management, ruling out concern for malignancies in high-risk patients, and streamlining care. It should be considered in all patients with upper airway complaints resistant to conventional treatment, with atypical complaints, and those at increased risk for cancer, such as smoking and alcohol use.

\section{Conclusion}

FNEP facilitate effective care of patients in a family medicine center with most patients having improvement of symptoms and only $20 \%$ requiring referral to a specialist. Thus, these procedures can be safely taught and performed in family medicine residency centers and should be considered, especially in areas where access to specialists is limited.

CORRESPONDING AUTHOR: Address correspondence to Dr John Malaty, Associate Professor, University of Florida Department of Community Health and Family Medicine, 1707 N. Main Street Gainesville, FL 32609. 352 246-8379. Fax: 352-265-9584. malaty@ufl.edu.

\section{References}

1. Corey GA, Hocutt JE Jr, Rodney WM. Preliminary study of rhinolaryngoscopy by family physicians. Fam Med. 1988;20(4):262-265.

2. Wilkins T, Gillies RA, Getz A, Zimmerman D, Kang L. Nasolaryngoscopy in a family medicine clinic: indications, findings, and economics. J Am Board Fam Med. 2010;23(5):591-597. doi:10.3122/jabfm.2010.05.090186

3. Aremu SK. Flexible nasopharyngolaryngoscopy: evaluation and appraisal of its effectiveness and diagnostic yield, The Nigerian experience. J Family Med Prim Care. 2019;8(10):33993403. doi:10.4103/jfmpc.jfmpc_489_19

4. Paul BC, Chen S, Sridharan S, Fang Y, Amin MR, Branski RC. Diagnostic accuracy of history, laryngoscopy, and stroboscopy. Laryngoscope. 2013;123(1):215-219. doi:10.1002/ lary.23630
5. Vardar R, Varis A, Bayrakci B, Akyildiz S, Kirazli T, Bor S. Relationship between history, laryngoscopy and esophagogastroduodenoscopy for diagnosis of laryngopharyngeal reflux in patients with typical GERD. Eur Arch Otorhinolaryngol. 2012;269(1):187-191. doi:10.1007/ s00405-011-1748-y

6. Brook C, Noordzij JP, Russell K, Aliphas A, Platt M. Predictive findings of allergic disease in fiberoptic nasolaryngoscopy. Laryngoscope. 2015;125(2):286-290. doi:10.1002/lary.24880

7. Abou-Elhamd KE, Sayed RH. Assessment of nasal obstruction with flexible nasal endoscopy. Saudi Med J. 2006;27(12):1850-1852.

8. James SL, Abate D, Abate KH, et al; GBD 2017 Disease and Injury Incidence and Prevalence Collaborators. Global, regional, and national incidence, prevalence, and years lived with disability for 354 diseases and injuries for 195 countries and territories, 1990-2017: a systematic analysis for the Global Burden of Disease Study 2017. Lancet. 2018;392(10159):17891858. doi:10.1016/S0140-6736(18)32279-7

9. Johnston KJ, Wen H, Joynt Maddox KE. Lack of access to specialists associated with mortality and preventable hospitalizations of rural Medicare beneficiaries. Health Aff (Millwood). 2019;38(12):1993-2002. doi:10.1377/ hlthaff.2019.00838

10. Vickery TW, Weterings R, CabreraMuffly C. Geographic distribution of otolaryngologists in the United States. Ear Nose Throat J. 2016;95(6):218-223. doi:10.1177/014556131609500607

11. Warshaw R. Health disparities affect millions in rural US communities. Washington, DC: Association of American Medical Colleges; October 2017. Accessed: May 7, 2021. https:// www.aamc.org/news-insights/health-disparities-affect-millions-rural-us-communities

12. Porter M, Malaty J, Michaudet C, Blanc P, Shuster JJ, Carek PJ. Outpatient referral rates in family medicine. Am J Accountable Care. 2018;6(1):25-28

13. Gwynne M, Page C, Reid A, Donahue K, Newton W. What's the right referral rate? Specialty referral patterns and curricula across I3 Collaborative primary care residencies. Fam Med. 2017;49(2):91-96.

14. Prout MN, Sidari JN, Witzburg RA, Grillone GA, Vaughan CW. Head and neck cancer screening among 4611 tobacco users older than forty years. Otolaryngol Head Neck Surg. 1997;116(2):201-208. doi:10.1016/S01945998(97)70326-7

15. Seccia V, Dallan I, Massimetti G, et al. Patientrelated and ENT-related predictive factors based on the pain experienced during flexible nasendoscopy. Laryngoscope. 2014;124(7):16481652. doi:10.1002/lary.24535 